\title{
WebWatch
}

\section{Planet of the Plants}

While zoologists may quibble with calling Earth the "plant planet," there are few other things at the informative Plant Pedia site that anyone else could find fault with. Its essay-based format and (apparently) intentionally unfocused front-page coverage make Plant Pedia, arguably, one of the more interesting sites to read about plants. Visitors will notice on the opening page a potpourri of topics, ranging at press time from metabolic pathways to the biological effects of essential oils. What makes it all work is the site's categorization of articles into hyperlinked "Label" categories, providing an underlying organization to an otherwise free-form mix. The overall result is an interesting, diverse site that will appeal to plant lovers at all levels.

[www.plant-pedia.com/]

\section{Bed Bug Bytes}

Described by some as the most hated insect in America, bed bugs are on the rise and the news is keeping people up at night, both literally and figuratively. Taking a lead role in disseminating important information about these annoying pests is the EPA. Their Bed Bug Information site wins major points for its informative pictures, descriptions, and links all squeezed onto a single, long running page. Visitors will probably be relieved to learn that bed bugs don't transmit disease, even as they are disgusted by pictures of them on bedding material. Best of all, the site offers strategies for preventing infestations and treatments for eliminating them if they occur. [www.epa.gov/bedbugs/]

\section{If You Can’t Beat ‘em, Eat'em}

Of course not all insects should be targeted for elimination. Bees, for example, are essential for pollination of many important food crops. Marc Dennis is taking a radically different approach to insects and food. Known as entomophagy and described on his website, Insects Are Food, Dennis posits the not at all subtle hint in the minds of visitors that insects may be the next big human protein source. Quoting Food and Agriculture Organization of the UN, the

\section{More Matters}

It's a message everyone has heard: Fruits and vegetables are good for you and an essential part of a healthy diet. Yet American diets are still deficient in these items. Like other advice taken for granted, such as the need to get annual flu shots, regular exercise, and adequate sleep, repetition and reinforcement are important for changing behavior. Aiding in the process is the Fruits and Veggies More Matters (FVMM) site, which advocates eating half-plates of vegetables as it encourages visitors with its makeover challenges. From

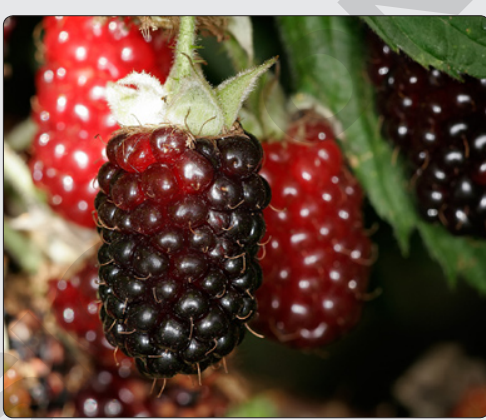

Photograph of boysenberries, courtesy of FruitsAndVeggiesMoreMatters.com. Copyright ${ }^{\oplus} 2011$ shopping plans to recipes, all while placing a significant emphasis on children, FVMM hits on all cylinders in its notable, worthwhile quest to improve the American diet.

[www.fruitsandveggiesmorematters.org]

site's opening page notes that there are 1462 species of "recorded edible insects." The actual number is likely far larger, given that $80 \%$ of the species on Earth are bugs of one sort or another. Marc's site spans the gamut from the latest news to the newest recipes with a dash of historical perspective. Many will find it surprising that insects have been an important human food source for tens of thousands of years and that they are commonly eaten today in developing nations around the world.

[http://insectsarefood.com/]

\section{Fuel Cells}

Though we are a long way from effectively growing fuel-producing plants in our backyards, the biofuel industry continues unabatedly gaining steam in farmlands (and other places) by producing a wide-ranging group of compounds from plant and microbial sources. Tracking those developments is the University of Minnesota Biofuels Database. Here one can view both the final biofuel products as well as relevant metabolic pathways giving rise to them. Coverage includes relevant enzymes, chemical catalysts, a gallery of organic chemical structures, organisms, and a glossary of terms.

[www.biofuelsdatabase.org/wiki/index. php5/Main_Page]

\section{Songs of Science}

Most of us learned the alphabet by singing it to the tune of "Twinkle, Twinkle Little Star," most likely owing to the ease with which the melody aided memorization of the sounds of the letters. Even if there is no educational link between music and learning, there is little doubt of the link between music and fun, as will be rapidly discovered by visitors to Greg Crowther's Sing About Science database. Spanning all ages and every major scientific disciplines, Sing About Science contains links to thousands of science songs (many of them free) that are available around the web. Search criteria of the database include keywords, songwriter, title, and age of target audience.

[www.singaboutscience.org/]

Written by Kevin Ahern,Ph.D. Please send web site recommendations to ahernk@orst.edu. [i]

BioTechniques 51:297 (November 2011)

doi 10.2144/000113759

To purchase reprints of this article, contact: biotechniques@fosterprinting.com 